\title{
Stigmatizing and Excluding HIV/ AIDS Patients Through Language in Cameroon
}

\author{
Gilbert Tagne Safotso \\ Department of English, University of Maroua, Cameroon
}

\begin{abstract}
Over the past thirty years, the world has been struggling to combat HIV/ AIDS, which in some parts of the globe, rather continues to cause serious ravages. In Cameroon, where the rate of infection ranges from four to seven per cent, depending on the region, a rich coded language has developed to discuss this disease. This paper examines that language to show how it contributes to stigmatize and exclude HIV/ AIDS patients. Results of data collected through informal talks and questionnaire $(\mathrm{N}=200)$, reveal that Cameroonians generally use euphemistic language to stigmatize and ostracise those who suffer from this epidemic. The paper concludes by proposing some positive language which can help ease the sufferings and integrate this group of marginal citizens, for their better contribution in the development of the country.
\end{abstract}

Keywords: HIV/ AIDS, stigmatize, exclude, disease, euphemistic

\section{INTRODUCTION}

In many parts of the world, and especially in Africa and Asia, despite the tremendous progress of medicine in the fight against HIV (Human Immunodeficiency Virus) and AIDS (Acquired Immune Deficiency Syndrome), because related to sex, it continues to be considered a taboo disease/ subject [ Lwanda 2003; Horne, 2004; Mawadza 2004; Moto 2004; Uys et al. 2005; Batibo \& Kopi 2008; Rodrigo \& Rajapakse 2009]. Batibo \& Kopi [2008: 69] note that sex matters are embarrassing phenomena in Setswana communities, and are not usually talked about. But because they have been brought to the open by the incidence of HIV/ AIDS pandemic, with more open discourse on sex-related matters in Botswana, more euphemisms have been created to camouflage the embarrassing nature of the various referents in the field.

Quoting Pretoria News of 4 July 2003, Horne [2004: 402] says that "the very words HIV or AIDS arouse superstition, and have become taboo". In South Africa, she remarks that AIDS is vaguely referred to as 'this thing', 'a person died of this thing', 'this thing outside'. Still in South Africa, Leclerc-Mdlala [2000] observes that the disease is called 'the three words' while Posel [2004] notes that it is called 'the new sickness'. In African societies, in general, people refer to HIV/ AIDS and sex matters with euphemistic terms. Epoge [2013: 4] for example, notes that in Cameroon, penis is referred to as king of glory, master of ceremony, Pa Joe, rector of female, family jewel, etc. while vagina is called among others mouse trap, Jerusalem, place of pleasure, hole of pleasure, garden of Eden. In Cameroon, to avoid stigma, many people who suffer from AIDS generally talk on television with face covered. On radio, they use a borrowed name. Some employers do not hesitate to sack their employees if they suspect that they are HIV positive or AIDS sufferers. Rodrigo \& Rajapakse [2009] remark that in South Asia, the patient and family face social isolation and ostracism. As they continue, this marginalisation as 'us' and 'them' can cause a significant problem in the control of the disease as people shy away from voluntary disclosure and testing. 
Citing the Joint United Nations Programme on HIV/AIDS [2002] and Policy Project [2003], Lesko [2005:20] says that stigma can be either internal or external. External stigma refers to actual experiences of discrimination. This may include the experiencing of domination, oppression, the exercise of power or control, harassment, categorising, accusation, punishment, blame, devaluing, prejudice, silence, denial, ignorance, anger, a sense of inferiority, social inequality, exclusion, ridicule, resentment or confusion. Internal stigma is the shame associated with HIV/AIDS and fear of being discriminated against. It is a powerful survival mechanism to protect oneself from external stigma, and often result in the refusal or reluctance to disclose HIV status or the denial of HIV/AIDS and unwillingness to seek help [Lesko 2005: 21].

From the sociolinguistic and discourse analysis frames, this paper examines the language used in Cameroon to discuss HIV/AIDS, stigmatise and exclude those who suffer from this disease. Given the complex linguistic landscape of the country, the analysis mainly looks at expressions used in English and French, which are the two official languages of Cameroon. This is completed by those used in Cameroon Pidgin English, which is the major lingua franca of the country.

\section{METHODS}

The data analysed come from informal talks with some HIV/AIDS patients, some medical staff, and from a questionnaire administered to 200 sexually active subjects. Given the delicacy of the topic, only five HIV/AIDS patients accepted to take part in the talks. The investigator met them at what is known in Cameroon as 'Day Hospital', at Yaounde Central Hospital. In some Cameroonian hospitals, the 'Day Hospital' is a ward where HIV/AIDS patients go at regular periods to take their retro-antiviral drugs and do their medical check up. Three medical doctors and ten nurses involved in HIV/AIDS treatment from the Bafoussam and Buea Regional Hospitals accepted to discuss the topic. The 200 sexually active subjects comprised 120 women and 80 men aged between 22 and 60 from Bamenda, Buea, Bafoussam, Yaounde and Maroua, which are some of the major Cameroonian towns. The questions of the informal talks and questionnaire aimed at knowing the various attitudes people have in Cameroon towards HIV/AIDS patients, and at eliciting the coded language they use in Cameroon French, Cameroon English and Cameroon Pidgin English to discuss HIV/AIDS. The patients were asked to express what / how they feel when they hear such language. The aim of the last question of the questionnaire was to elicit some positive language the participants thought could be used to make HIV/AIDS patients feel as full and important members of society. The next section examines the data collected.

\section{RESULTS}

This section looks at the various coded expressions that are commonly used in Cameroon French, Cameroon English and Cameroon Pidgin English to discuss HIV/AIDS, stigmatize and exclude those who suffer from this disease. In each of the languages, the coded word or expression is given, then, its British English version is attempted. Table 1 below presents the expressions in Cameroon French. 
Table 1. Coded expressions used in Cameroon French to name HIV/AIDS and its patients

\begin{tabular}{ll}
\hline Words or expressions & British English version \\
\hline Le si & AIDS \\
Malchance & Ill-luck \\
Tombeau ouvert & Open grave \\
Il / elle a le si & He / she suffers from AIDS. \\
Maladie du jour & The disease in fashion \\
Quatre lettres & Four lettres \\
Sept + un & Seven + one \\
Poison lent & Slow poison \\
Mort vivant & Living dead \\
Il / elle a avalé le plastic. & He / she swalowed plastic. \\
Il / elle a la maladie là. & He / she has that disease. \\
Il / elle a le machin-là. & He / she is suffering from that thing. \\
La maladie qui est dehors & The disease which is outside \\
Il / elle a la maladie qui est dehors. & He / she has the disease which is outside. \\
Ce qui est dehors & What is outside \\
Il / elle a attrapé ce qui est dehors. & He / she caught what is outside. \\
La grande maladie & The big disease \\
\hline
\end{tabular}

The expressions listed above are not exhaustive, and just represent the tip of the iceberg. The repertoire of the coded language used to talk of HIV/AIDS in Cameroon French is quite vast. Over the past thirty years of existence of the disease, because of the ravages it has been causing in many Cameroonian families, many people have been talking about it with a lot of caution. Generally, it can be remarked that, to talk about those who suffer from HIV/AIDS, the disease is almost never openly named. Expression such as 'il / elle a avalé le plastic (He /she swallowed plastic); il / elle a le machin-là (he /she has that thing); il / ell a atrapé ce qui est dehors (he / she caught what is ouside) can only be understood by Cameroonians. Almost all the expressions used to talk of HIV/ AIDS and its sufferers here are euphemistic. People fear calling the disease by its name. "Ce qui est dehors (what is outside), or la maladie qui est dehors (the disease which is outside) means that HIV /AIDS is so frightful that it should remain outside, i.e. with other people, never with 'me' or 'us'. Calling HIV / AIDS patients 'tombeau ouvert (open grave), mort vivant (living dead) is a clear way of excluding them from society as the graves are found in cemeteries as well as their occupants. In Cameroon, people would talk of seropositivity or AIDS only when they are sure that there is nobody suffering from it or their relatives around them. Table 2, which follows, lists the coded expressions used in Cameroon English. 
Table 2. Coded expressions used in Cameroon English to name HIV/AIDS and its patients

\begin{tabular}{lc}
\hline Words or expressions & British English version \\
\hline Boarding pass & HIV/ AIDS \\
Departure lounge & $/ /$ \\
Seven + one & AIDS which is synonymous with eight \\
Four + four & $/ /$ \\
Nine- one & $/ /$ \\
Fallen hair & Disease that destroys hair \\
Last hour & Disease that will kill the patient very soon \\
High class & Disease that is above all other diseases \\
What is taking people away & HIV/ AIDS \\
Rotten & Person whose body is destroyed by AIDS \\
\hline
\end{tabular}

As it can be observed, Cameroon English has very few coded expressions to name HIV/ AIDS and those who suffer from it. This is because, unlike French-speaking Cameroonians, when two English-speaking Cameroonians meet, they readily use Pidgin English to show their brotherhood. So, sensitive topics like that of HIV/ AIDS are better discussed in Cameroon Pidgin English like other current matters. Nevertheless, the few coded expressions used in Cameroon English are as significant as those discussed in Cameroon French above. The name of the disease is camouflaged, and is replaced by euphemistic expressions such as 'boarding pass', 'departure lounge', which rather refer to air transport. Other expressions such as 'last hour', 'high class' or 'rotten', in their literal meaning has nothing to do with HIV/ AIDS or its patients. Yet, their use has a lot of psychological effects on patients. The medical doctors and nurses who took part in the study all acknowledged that, many patients come to the hospital at a late stage of the disease, because they see the confirmation of their new status as a death sentence. At the beginning, some patients even refuse their seropositivity and the drugs prescribed, because of self-stigmatization. This kind of situation is simply aggravated when patients hear some of the expressions studied so far. The coded phrases used in Cameroon Pidgin English to name HIV/AIDS are contained in the table below. 
Table 3. Coded expressions used in Cameroon Pidgin English to name HIV/AIDS

\begin{tabular}{ll}
\hline Words or expressions & British English version \\
\hline Sick fo die & Deadly disease \\
Mblakot sick & Penis disease \\
Waka waka & From one person to another \\
Rich man sick & Disease of rich people \\
Sweet sick & Sweet disease \\
Dog sick & Bitch disease \\
Nyanga sick & Beauty/ coquetishness disease \\
High fiva & High fever \\
Sick fo fuck & Love/ sexual intercourse disease \\
Cool die & Cool death \\
Slow die & Slow death \\
Bad sick & Bad disease \\
Strong sick & Hard disease \\
Sick fo outside & Outside disease \\
\hline
\end{tabular}

As illustrated by Tables $3 \& 4$ (below), Cameroon Pidgin English has the highest number of coded expressions to name HIV/AIDS, and to talk of its patients. Like those discussed in Cameroon French and Cameroon English, all the expressions listed in the table above are euphemistic. Some of them such as 'sick fo die (deadly disease), cool die (cool death), bad sick (bad disease) are frightful while others are crude, e.g. 'mblakot sick (penis disease), sick fo fuck (love, sexual intercourse disease). Some of the expressions are allusive, mocking, and even ridiculous, e.g. 'rich man sick (disease of rich people), nyanga sick (beauty/coquetishness disease), sweet sick (sweet disease), but none of them mentions HIV/AIDS, as if they wish to silence it. An expression like 'sick fo outside' (outside disease), would even imply that HIV/AIDS is for others, and should remain outside. In South Africa, Horne [2004] remarks that a similar appellation is used for HIV/AIDS. It is called 'this thing outside'. Table 4 which follows, looks at the coded expressions used to talk of HIV/ AIDS patients in Cameroon Pidgin English. 
Table 4. Coded expressions used in Cameroon Pidgin English to talk of HIV/AIDS Patients

\begin{tabular}{ll}
\hline Words or expressions & British English version \\
\hline e get high fever. & He / she has high fever. \\
e de sick posh belle. & He/she is suffering from diarrhoea. \\
e don catch dat new sick. & He/she caught that new disease. \\
e di sick dat bad sick. & He/ she is suffering from that bad disease. \\
e di sick fo die. & He/ she is suffering to die. \\
e no free fo yellow fever. & He/ she is trapped by yellow fever. \\
e de sick corocoro. & He /she is suffering from scabies. \\
e di take control medicine. & He/ she is taking regulatory medicine. \\
Wata no stand fo yi belle & Water does not last in his/her stomach. \\
Yi time don reach. & His/ her time has come. \\
e de take allowance. & He / she is taking antiretroviral drugs. \\
Yi blood don spoil. & His/her blood is destroyed. \\
e de take anti. & He/ she is taking antiretroviral drugs \\
e get posh posh. & He / she has water stools. \\
e don getam. & He/ she has caught it. \\
e di take control. & He/ she is taking regulatory medicine. \\
e don catch cam no go. & He/ she has caught the incurable disease. \\
na distributor. & He/ she is an HIV/AIDS spreader. \\
e get dat big sick. & \\
\hline
\end{tabular}

Like the expressions analysed in Table 3, in those listed above, the acronym HIV/AIDS is avoided. Many of them are either insulting or mocking, e.g. ' $e$ de sick posh belle (he/ she is suffering from diarrhoea); e de sick fo die (he/ she is suffering to die); e de sick corocoro (he/ she is suffering from scabies); yi time don reach (his/her time has come); na distributor (H/she is an HIV/ AIDS spreader). An expression like 'e de take anti (he/she is taking antiretroviral drugs), in its literal meaning, even looks sympathetic as 'anti' in Cameroon Pidgin English means 'aunt'. But in the domain of HIV/AIDS, the term is quite offensive as someone cannot be 'drinking' his aunt. Another expression such as 'e don getam' (he/she has caught it) would imply that the thing it refers to is so popular that everybody knows what disease the speaker is talking about. It also expresses desolation as the disease is fatal.

\section{What positive language and attitude to integrate hiv/aids patients in cameroon?}

The fact that a World AIDS Day continues to be organised around the globe (the first edition took place in 1988), shows that this disease is still a threat for humanity, and will still be for a good number of years in future. The theme of the celebration on $1^{\text {st }}$ December 2015, was "Getting to Zero", Zero New HIV Infections, Zero Discrimination, Zero AIDS-related Deaths, meaning that new infections continue to occur, and that many communities do not yet accept it. According to World Health Organization, in 2011, more than 34 million people around the world were living with HIV /AIDS. In, 2013 the organization reported that almost 70 million people had been infected by HIV, and about 35 million had died of AIDS since the beginning of the pandemic in the early 1980s. This situation, in 2017, has probably not 
changed a lot. Indeed, three of the five AIDS patients who accepted to take part in this research, continued to see themselves as outcasts and dregs of society. Despite the drugs they had come to take at the hospital, there was some sense of being trapped, anger and bitterness in their look and speech. So, given that we still have to co-habit with HIV/ AIDS patients for years or decades, the use of a positive language that will enable to accept and integrate them is necessary.

In his book titled Clouds move, the South African seropositive Derrik Fine [2007: 223-229] suggests a number of instances of positive language. For example, he proposes 'person living with HIV or person who has HIV' for 'HIV positive person or HIV infected person'; 'people living with HIV' for 'HIV sufferers or AIDS carriers'; 'HIV' for 'AIDS virus'. Looking at Fine's positive language, person living with HIV would mean that you can live with HIV like any other chronic disease. Using HIV for AIDS means that not all HIV infections will lead to AIDS. From the data gathered through the questionnaire and the various talks with the informants of this study, much cannot be added to these examples of positive language. Many respondents acknowledged the necessity of a positive language towards the HIV/AIDS patients, but were unable to clearly formulate it. Some informants contented themselves with vague expressions like 'mon frère' (my brother), 'ma soeur' (my sister), 'mon ami' (my brother), they said can be used to call the patients. In the Cameroonian context, these appellations, which in fact are just familiarity expressions, can work somehow. Generally, in Cameroonian extended families and in the streets, to flatter people one is not closer to, they call them ami, soeur, frère, sister, brother, bro to have their favour. Many participants rather insisted on the positive attitude that society should adopt viv-à-vis HIV/ AIDS patients. They suggested that people living with the disease be integrated in all social activities, that they be told that their disease is just like any other disease, that by taking their anti-retroviral drugs they can live normally. In addition, patients who stigmatize or victimize themselves should deserve a special attention, and possibly be given (whenever possible) some jobs that will take them out of their isolation by making them mingle with other members of society.

\section{CONCLUSION}

This paper looked at some of the coded words and expressions used in Cameroon French, Cameroon English, and Cameroon Pidgin English to discuss, stigmatize and exclude HIV/ AIDS patients. The expressions analysed are all euphemistic. In the three languages in questions, people avoid to call the disease by its name. They use euphemistic terms, which go from neutral expressions to crude, mocking and insulting ones to call the disease and its patients. This type of behaviour is the evidence that, despite the tremendous efforts put in place by WHO (World Health Organisation) and individual countries around the world, HIV/AIDS remains a frightful disease that should not be called by name for fear (perhaps) to catch it or to invite it to one's house. Patients that society mocks at, insults, stigmatizes and excludes are however, important members of society, who by taking their anti-retroviral drugs properly could be healthier than some diabetic or cancer patients. The few positive expressions suggested above might perhaps help. But the lack of clear positive expressions that can help accept and integrate the patients is an indication that the disease is still terrifying. The Cameroonian society still has a pessimistic look at the disease, as nobody has ever seen anyone totally recovering from it. So, positive words and expressions that would help accept and integrate HIV/ AIDS patients in Cameroon (and perhaps in other African societies) are still to be imagined. .Examples such that of Derrick Fine mentioned in Section 4 are already to be encouraged, and to be copied by HIV/AIDS patients for their self-esteem and better integration. 


\section{References}

Batibo, H. M. \& Kopi, M. M. [ 2008 ]. The Nature and Origin of Sex- Related Euphemism in

Setswana. Marang: Journal of language and Literature, 18, 69-83. http/dx.doi.org/10.4314/marang.v18i1.39327.

Epoge, N.K. [ 2013 ]. Euphemism in Cameroon English: Sweet Talk or Deception? International Journal of Inovative Interdisciplinary Research, 2 [ 2 ], 1-10.

Fine, D. [ 2007 ]. Clouds move-My journey of living openly with HIV. Kommetji: The Openly Positive Trust.

Horne, F. [ 2004 ]. Some Aspects of AIDS-related Discourse in Post-apartheid South African Culture. Alternation, $11[2$ ], 401-419.

Leclerc-Mdlala, S. [ 2000 ]. Silence, AIDS and Sexual Culture in Africa. AIDS Bulletin, 9 [ 3 ], 27-30.

Lesko, I. [ 2005 ]. Attitudes and Beliefs around HIV and AIDS Stigma. The impact of the Film 'The Sky in her Eyes'. [ Unpublished Masters in Development Studies thesis ]. CapeTown: University of the Western Cape.

Lwanda,, J. [ 2003 ]. The [In]visibility of HIV/AIDS in the Malawi Public Sphere. African

Journal of AIDS Research, 2 [ 2 ], 113-126. DOI: 10.2989/16085906.2003.9626566.

Mawadza, A. [ 2004 ]. Stigma and HIV/ AIDS Discourse in Zimbabwe. Alternation, 11[ 2 ],420-439.

Moto, F. [ 2004 ]. Towards a Study of the Lexicon of Sex and HIV/ AIDS. Nordic Journal of African Studies, 13 [ 3 ], 343-362.

Posel, D. [ 2004 ]. Sex, Death and Embodiment: Reflections of the Stigma of AIDS in Agincourt, South Africa. Paper Presented at WISER Symposium held at the University of Witwatersrand, 14-16 October 2004.

Rodrigo, C. \& Rajapakse, S. [ 2009 ]. Current Status of HIV/AIDS in South Asia. Journal of Global Infectious Diseases, 2 [ 2 ], 93-101. DOI: 10.4103/0974 -777.56249.

UNAIDS. [ 2002 ]. Situational Analyses of Discrimination and Stigmatisation against People Living with HIV/AIDS in West and Central Africa. Ethical and Legal Considerations. Geneva.

Uys, L. et al. [ 2005 ]. “Eating Plastic', 'Winning the Lotto', 'Joining the WWW'. Descriptions of HIV/ AIDS in Africa. Journal of the Association of Nurses in AIDS Care, 16 [ 3 ], 11-23. DOI: 10.1016/ jana 2005.03.002. 